\title{
A Rare Form of Intraductal Papillary Mucinous Carcinoma
}

\author{
Reiko Yamada ${ }^{1}, K$ enichiro Nishikawa ${ }^{2}$, Kyosuke Tanaka $^{3}$ and Junya Tsuboi ${ }^{3}$
}

Key words: intraductal papillary mucinous neoplasm, intraductal papillary mucinous carcinoma, pancreatic cyst, endoscopic transpapillary drainage, cystic infection

(Intern Med 58: 451-452, 2019)

(DOI: 10.2169/internalmedicine.1250-18)

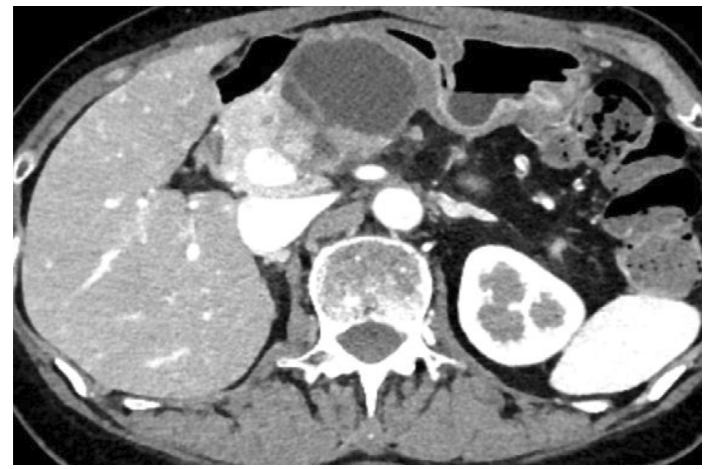

Picture 1.

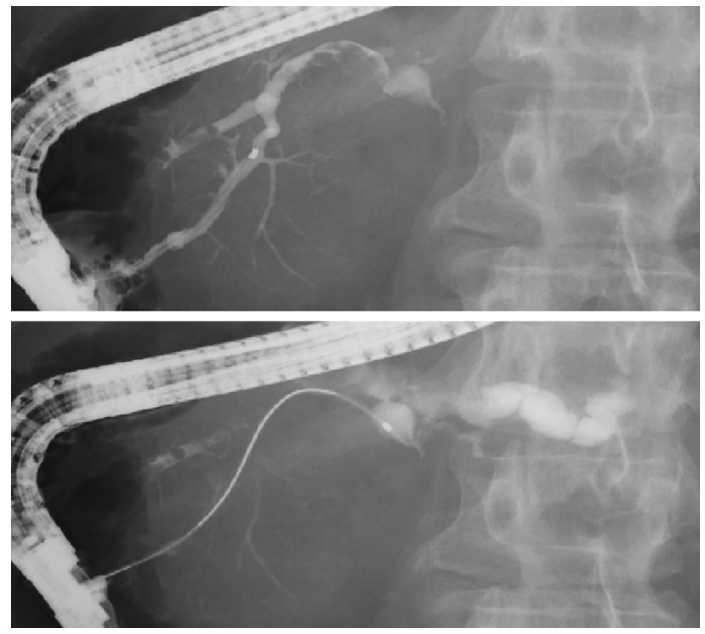

Picture 3.

A 69-year-old-woman presented with febrile epigastric pain. A laboratory analysis indicated inflammation (WBC, 19,000/ $\mu \mathrm{L}$; CRP, $34.64 \mathrm{mg} / \mathrm{dL})$. CT showed a 50-mm cyst and an enhanced mass in the pancreatic head (Picture 1). MRI demonstrated a fluid-fluid-level inside the cyst with
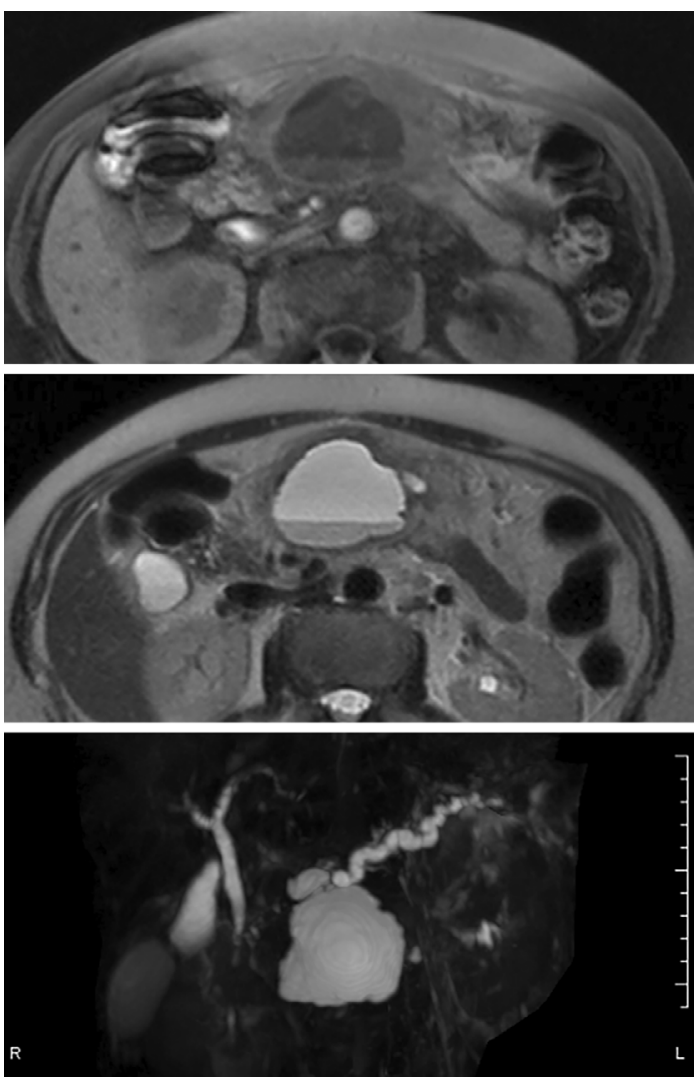

Picture 2.

edematous wall-thickness (Picture 2). Endoscopic retrograde pancreatography showed the irregular pancreatic duct leading to the cyst (Picture 3). Endoscopic transpapillary nasopancreatic drainage (ENPD) was performed; her symptoms were alleviated and the cyst became smaller. Pancreaticoduodenectomy was performed based on a cytological diagnosis of adenocarcinoma. The histological examination showed a 29-mm-mass occupying the pancreatic duct; which was well-differentiated papillary adenocarcinoma. Inside the

${ }^{1}$ Department of Gastroenterology and Hepatology, Mie University Hospital, Japan, ${ }^{2}$ Matsusaka City Hospital, Japan and ${ }^{3}$ Department of Endoscopy, Mie University Hospital, Japan

Received: March 29, 2018; Accepted: July 16, 2018; Advance Publication by J-STAGE: September 12, 2018

Correspondence to Dr. Reiko Yamada, reiko-t@ clin.medic.mie-u.ac.jp 

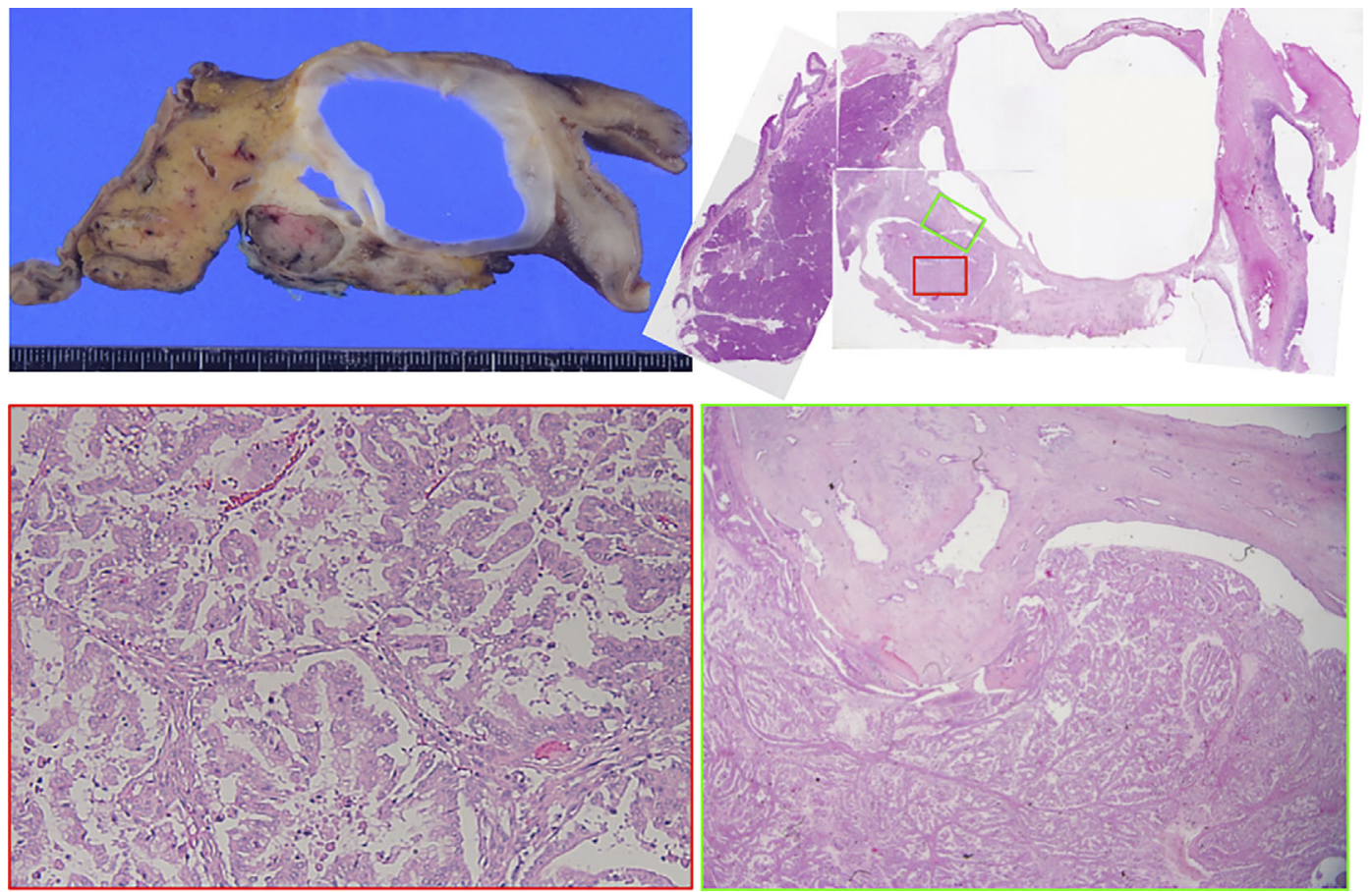

Picture 4.

cyst, pancreatic epithelia were observed (Picture 4). The diagnosis was invasive intraductal papillary mucinous carcinoma with retention.

A fluid-fluid-level is rarely observed in a pancreatic cyst, but when it is seen it normally suggests an infection. Although cystic infection is a rare complication of pancreatic tumors, puncture is associated with a high risk of seeding. ENPD is highly recommended as an initial intervention (1).

\section{Reference}

1. Watanabe K, Karasaki H, Mizukami Y, et al. Cyst infection of intraductal papillary mucinous neoplasms of the pancreas: management of a rare complication: report of 2 cases. Pancreas 43: 478$481,2014$.

The Internal Medicine is an Open Access journal distributed under the Creative Commons Attribution-NonCommercial-NoDerivatives 4.0 International License. To view the details of this license, please visit (https://creativecommons.org/licenses/ by-nc-nd/4.0/).

The authors state that they have no Conflict of Interest (COI).

(C) 2019 The Japanese Society of Internal Medicine Intern Med 58: 451-452, 2019 